\title{
Update in the Surgical Management of Decubitus Ulcers
}

\section{So ia Diaz, Xiaoyi Li, Lourdes Rodríguez and Christopher J Salgado*}

DeWitt-Daughtry Family Department of Surgery, Division of and Plastic and Reconstructive Surgery, University of Miami Miller School of Medicine, Miami, Florida, USA

\begin{abstract}
Decubitus ulcers remain a common and recurring problem amongst overly ill patients, especially those who are bed-bound. They are caused by unrelieved pressure over tissues, mainly over bony prominences, such as the trochanteric, ischial, and sacral areas, and are classified from stage I to IV. Many forms of management have been described, with prevention being the most important of them. For stages I and II a conservative, non-surgical approach can be used, compared to stages III and IV which normally require surgical management. Post-operative care has also been shown to play a major role in avoiding the high rate of recurrences. Because of their location, high recurrence rates and increase in mortality, pressure sores continue to be a challenge for the medical and nursing staff, and are extremely costly to treat. In this manuscript we review the literature to expose the latest non-surgical and surgical techniques for the management of Decubitus Ulcers.
\end{abstract}

Keywords: Decubitus ulcers; Osteomyelitis; Tensor fascia lata; Wound care; Surgical management pressure sore

\section{Introduction}

Pressure ulcers, also known as decubitus ulcers or bed-sores, are defined as localized injuries to the skin and/or underlying tissue, usually over a bony prominence, as a result of pressure, or pressure in combination with shear and/or friction [1]. In a Cochrane Review, an incidence of $7 \%$ to $71.6 \%$, and a prevalence of $8.8 \%$ to $53.2 \%$ were reported [2]. In an acute care setting the incidence is between $5-9 \%$, and reaches $21 \%$ in critical care settings [3]. Levine et al. reported that $2 \%$ to $28 \%$ of nursing home residents suffer from pressure ulcers [4,5], and almost two thirds of these occur in elders above 70 years old. They are also common in patients with spinal-cord injury and that are bedbound $[1,6]$, reaching a $39 \%$ incidence in these patients [7].

Pressure sores can develop anywhere on the body, but are often located in the trochanteric, ischial, heel, and sacral areas [7]. Multiple classification systems have been described, as depicted in table 1 , but the one proposed by the National Pressure Sore Advisory Panel Consensus Development Conference (US-NOUAP) is the most commonly used [8]. It divides the lesions from Stage I to IV and Un-Stageable. Pressure sores, as their name implies, are caused mainly by external unrelieved pressure that exceeds the capillary pressure $(33 \mathrm{mmHg})$, leading to ischemic necrosis [1]. Other factors that have been found to contribute to the formation of pressure sores are shearing (causes tearing of blood vessels), friction (may breach the epidermis), moisture (causing maceration of the skin), neurological conditions, local infection, edema, and poor nutrition [1,8,9]. Cakmak et al. found that fecal and urinary incontinence, smoking, hypoalbuminemia, alcoholism, and diabetes mellitus were other factors that contribute to pressure sore development [10].

In general, the treatment of pressure sores begins with prevention (optimizing nutrition status, preventing/eradicating infection, and relieving pressure) [4,7,11]. According to Brem and Lyder [7] an interdisciplinary approach (physician, nurse, social worker) demonstrated to be more cost-effective. Pressure sores classified as stage I and II can be treated conservatively by using optimal non-surgical ulcer treatment and by eliminating the local and general conditions that interfere with healing. However, if stage III or IV pressure ulcers are present, surgical management is normally required [12].

Pressure sores continue to be a challenge for the medical and nursing staff because they are difficult to heal and to close by surgery, may have a tendency to recur and are extremely costly to treat. Chronic wound management however, particularly if in a wound care center, will lead to equivalent costs and may never get to the point of being a fully closed wound. They are also associated with a $>2$-fold increase in mortality [2,7], making them a potentially serious condition that should be treated.

The objective of this article is to expose a review of the latest techniques for the non-surgical and surgical pressure ulcers management.

\section{Management}

Management of pressure ulcers is challenging. There are many options of treatment, ranging from surgical to non-surgical. However, management should always be directed towards prevention, which is achievable by educating the patient and the medical and nursing staff about the multiple factors that contribute to the formation of pressure sores, and how to avoid them.

\section{Nonsurgical Management}

Nonsurgical management of pressure sores is typically reserved for stage I and stage II ulcers. The management can be separated into prevention of ulcer formation, optimizing local wound healing, and use of adjunctive treatments. Although multiple methods exist for each treatment category, there is generally little evidence that definitively supports one method above another.

Preventing the formation of pressure sores is the ideal treatment modality for patients [13]. Patient repositioning has long been used as a preventive method of pressure sores, whether through turning by

*Corresponding author: Christopher J Salgado, M.D, Professor of Surgery Division of Plastic and Reconstructive Surgery, DeWitt-Daughtry Family Departmen of Surgery, University Of Miami, Leonard Miller School of Medicine Clinical Research Building (CRB), 1120 NW 14 ${ }^{\text {th }}$ Street, Miami, FL 33136, USA, Tel: 305243-7500; Fax: 305-243-4535; E-mail: christophersalgado@med.miami.edu

Received June 11, 2013; Accepted June 27, 2013; Published July 03, 2013

Citation: Diaz S, Li X, Rodríguez L, Salgado CJ (2013) Update in the Surgical Management of Decubitus Ulcers. Anaplastology 2: 113. doi: 10.4172/2161 1173.1000113

Copyright: (c) 2013 Diaz S, et al. This is an open-access article distributed under the terms of the Creative Commons Attribution License, which permits unrestricted use, distribution, and reproduction in any medium, provided the original author and source are credited. 
Citation: Diaz S, Li X, Rodríguez L, Salgado CJ (2013) Update in the Surgical Management of Decubitus Ulcers. Anaplastology 2: 113. doi: 10.4172/2161-1173.1000113

Page 2 of 10

\begin{tabular}{|c|c|c|c|c|}
\hline Grade/stage & Shea (1975) & Yarkony-Kirk (1990) & EPUAP (1996) & US- NPUAP (2007) \\
\hline 1 & $\begin{array}{l}\text { Limited to epidermis exposing } \\
\text { dermis }\end{array}$ & Red area & Erythema & Redness \\
\hline II & $\begin{array}{c}\text { Full thickness skin loss exposing } \\
\text { fat }\end{array}$ & $\begin{array}{c}\text { Involvement of epidermisand } \\
\text { dermis, no subcutaneous fat } \\
\text { observed }\end{array}$ & Partial thickness skin loss & Partial thickness loss of skin \\
\hline III & $\begin{array}{c}\text { Full thickness skin and fat defect } \\
\text { exposing deep fascia }\end{array}$ & $\begin{array}{c}\text { Exposed subcutaneous fat with no } \\
\text { muscle observed }\end{array}$ & $\begin{array}{l}\text { Full thickness skin and } \\
\text { subcutaneous necrosis }\end{array}$ & $\begin{array}{l}\text { Full thickness skin loss exposing } \\
\text { subcutaneous fat }\end{array}$ \\
\hline \multicolumn{5}{|l|}{ IV } \\
\hline & $\begin{array}{l}\text { Full thickness defect exposing } \\
\text { bone }\end{array}$ & $\begin{array}{l}\text { Exposed muscle without bone } \\
\text { involvement }\end{array}$ & $\begin{array}{l}\text { Extensive destruction with or } \\
\text { without skin loss }\end{array}$ & $\begin{array}{l}\text { Full thickness tissue loss exposing bone, } \\
\text { tendon or muscle }\end{array}$ \\
\hline V & - & Exposed bone & - & - \\
\hline \multirow[t]{3}{*}{ VI } & - & Joint space involvement & - & - \\
\hline & $\begin{array}{l}\text { Closed pressure sores. } \\
\text { Subcutaneous necrosis without } \\
\text { skin ulceration }\end{array}$ & - & - & $\begin{array}{l}\text { Suspected deep tissue injury with discolored } \\
\text { intact skin }\end{array}$ \\
\hline & - & - & - & $\begin{array}{l}\text { Un-stageable: Full thickness tissue loss with } \\
\text { base covered with slough/ eschar }\end{array}$ \\
\hline
\end{tabular}

Table 1: Comparative table of common classifications of pressure ulcers [8]

nursing or through the use of specialized mattresses. Physiologically, patient repositioning reduces ischemia at pressure locations allowing for increased perfusion and decreased metabolic waste accumulation. Brem and Lyder recommend patient turning at least 2-3 times a day [7]. Despite the common practice of patient turning, there is no strong evidence to suggest the best protocol [14]. In addition, there are no randomized controlled trials or strong evidence studying whether repositioning makes a difference in pressure ulcer healing [2]. The use of specialized mattresses allows more frequent redistribution of pressure and functions similarly to repositioning. While one recent Cochrane review advocated the use of specialized mattresses [15], Reddy et al. did not find specialized mattresses to be superior compared to nonpowered mattresses [13]. Furthermore, specialized mattresses only reduce pressure but do not address other forces on ulcer formation such as friction, temperature, and shear.

Enzymatic debridement uses collagenase and urea amongst other enzymes over the wound. Biologic debridement uses maggots over the ulcer [16]. Optimization of local wound healing is another aspect of nonsurgical management. Wound healing techniques range from debridement of underlying tissue, dressing changes, to proper nutrition. Wound care protocols should target moisture balance, bacteria, and debridement. Many methods target the removal of dead tissue creating a proper wound bed for granulation tissues. Dressing changes control for appropriate drainage and absorption of wound debris. However, no single dressing has been found to be better than others [13]. Proper nutrition is also of paramount for wound healing. Vitamin $\mathrm{C}$ and Zinc are long known to be essential in the biochemical pathway for tissue regeneration. Furthermore, for patients with poor protein and albumin, restoring a proper nitrogen balance speeds up wound healing [17].

Adjuvant treatments for pressure ulcers include the use of newer technology to improve wound healing. Wound vacuum therapy, also known as negative pressure wound therapy, increases local blood supply and wound contraction. However, there is no actual strong evidence supporting the use of negative pressure wound therapy in the treatment of pressure ulcers $[18,19]$. Evidence for the use of hyperbaric oxygen has also been inconclusive [20]. Similarly, evidence for the use of lasers, ultrasound, electrotherapy, and electromagnetic therapy is also lacking [13].

\section{Surgical Management}

While stage I and stage II ulcers respond to conservative management, surgical intervention is usually required for stage III and stage IV ulcers. The goals of surgical management are to prevent progressive osteomyelitis, reduce protein loss, improve quality of life, improve function and hygiene, and reduce rehabilitation and wound care costs. These goals are typically achieved as patients undergoing surgical intervention have been shown to have significantly better outcomes. Singh et al. found that in spinal cord injury patients, surgical interventions led to improvements in quality of life, hemoglobin, serum albumin, and total serum protein [21]. Another study has also found improvements in hygiene as well as reduction in rehabilitation costs [1] (Figures 1 and 2).

Preoperative considerations include many factors such history of prior ulcers, ambulatory status, motivational status, compliancy, type of injury, and other associated medical problems. Other considerations during the preoperative phase are maintaining an albumin level above $2 \mathrm{~g} / \mathrm{dl}$ to ensure healing [8], radiographs to rule out pathologies like fractures, scoliosis or osteomyelitis, treatment of spasms, colostomies if the ulcers are in close proximity to the anus, and, according to the severity of the ulcer, prophylactic antibiotics one day prior to surgery and postoperative [22].

Debridement is the first process in surgical intervention. Even though recent Cochrane Reviews have not shown strong evidence of any debridement technique being the most efficacious [23], debridement can be achieved through a myriad of methods. The optimal method for debridement depends on factors such as location, perfusion status, and equipment needed [24]. Chemical debridement uses compounds such as Dakin solution. Mechanical debridement uses dressing changes along with wound cleansing. Surgical debridement should be conducted in the operating environment with proper wound cultures of exposed bones. Surgical debridement focuses on excision of ulcer, underlying bursa, surrounding calcifications, with removal of underlying heterotopic ossification that will be covered by a flap in addition to osteomyelitic bone. A combination of methods is also possible [4,25] (Figure 6).

Since pressure ulcers often penetrate to bony prominences leading to possible osteomyelitis, ostectomies are also a subject of debate in pressure ulcers. Bone debridement is typically conducted until appearance of bleeding, grossly healthy bone. Bone biopsy should be 
Citation: Diaz S, Li X, Rodríguez L, Salgado CJ (2013) Update in the Surgical Management of Decubitus Ulcers. Anaplastology 2: 113. doi: 10.4172/2161-1173.1000113
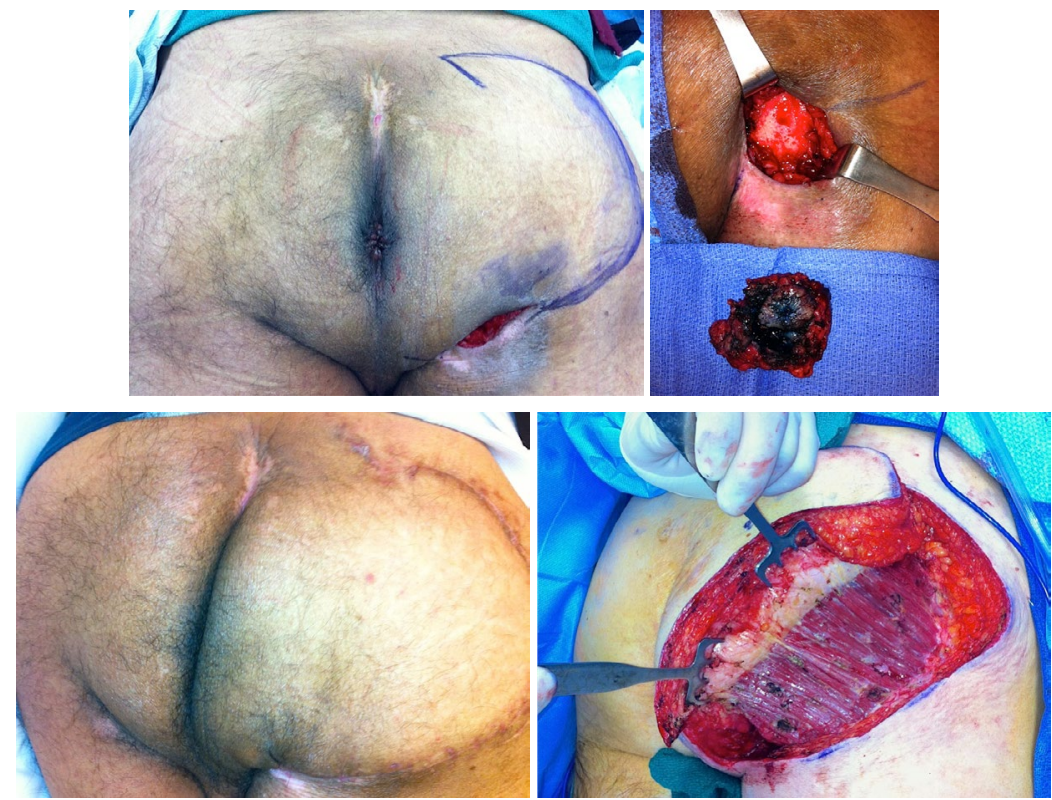

Figure 1: a) 46 year old male with lower extremity paresis and right ischial stage IV decubitis ulcer of 3 years duration. b) Intraoperative view at time of right ischialbursectomy and ischiectomy. c) Immediate reconstruction with gluteal rotation fasciocutaneous flap reconstruction. d) 5 months postoperative healed and without recurrence.
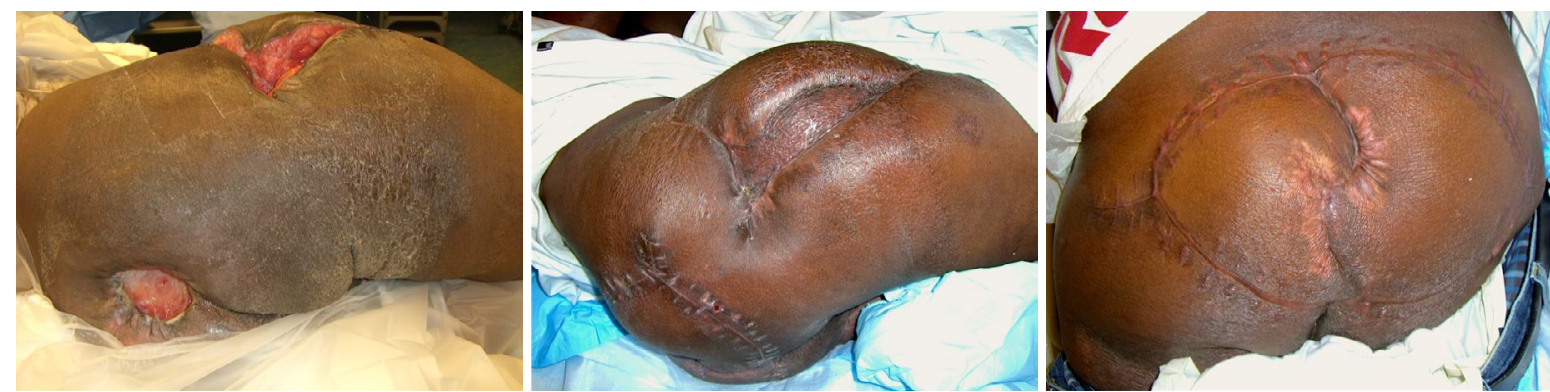

Figure 2: a) 28 year old male with lower extremity paresis and right trochanteric ulcer in addition to sacral ulcer both Stage IV. b \& c) 6 months following right vastuslateralis flap and skin graft in addition to bilateral VY gluteal fasciocutaneous flaps.
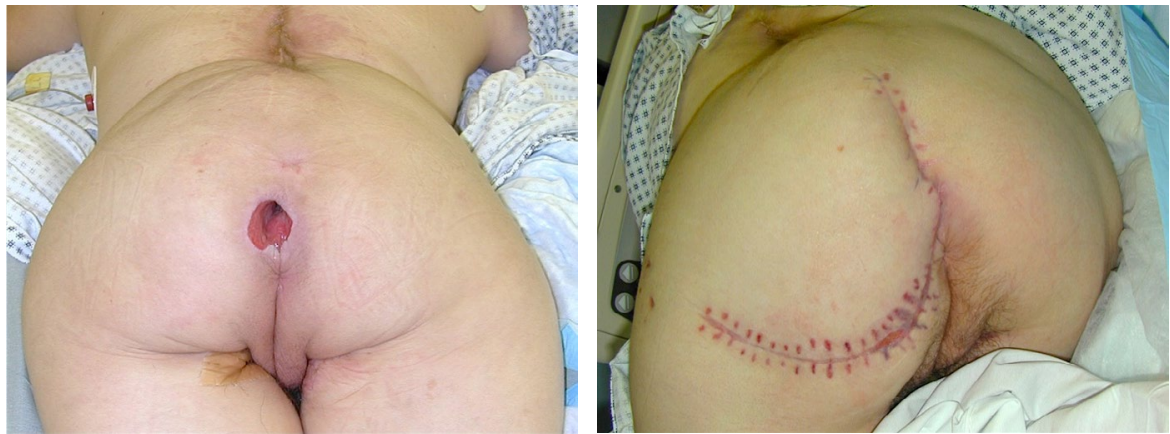

Figure 3: a) 15 year old female with spina bifida and Stage IV sacral ulcer of 2 years duration. b) Gluteal fasciocutaneous rotation flap at 3 months.

conducted to help guide in postoperative antibiotic use. The general consensus for optimal care is removal of as little bone as necessary. While some studies have shown ostectomy to be effective in reducing recurrences [26,27] and flap failures [28], others found no association between bone cultures, complications, and recurrences [29].

Many types of flaps are available as reconstructive techniques to cover pressure sores. Musculocutaneous flaps were the first flaps introduced for pressure sores and have become the second line choice in treatment if a fasciocutaneous flap has failed or there is a defect size which warrants a larger soft tissue fill where a musculocutaneous flap is required [30]. Theoretically, muscular flaps offer the advantage of elimination of underlying dead space, rich vascular supply, tissue 
Citation: Diaz S, Li X, Rodríguez L, Salgado CJ (2013) Update in the Surgical Management of Decubitus Ulcers. Anaplastology 2: 113. doi: 10.4172/2161-1173.1000113

cushioning, and enhanced bacterial clearing [31,32]. Studies have also shown that transferred muscle atrophies with up to $30 \%$ loss over time [33]. Muscle tissue, which is less tolerant to ischemia, may lead to earlier recurrence if it is subjected to a pressure environment once again. A systematic review by Sameem et al. reported a $18.6 \%$ complication rate, $9 \%$ necrosis rate, $7.5 \%$ infection rate, and $8.9 \%$ recurrence rate for musculoctaneous flaps. When taking musculocutaneous flaps, it is also important to remember the importance of donor morbidity, especially in non-paralyzed individuals, to preserve muscular function [34].

Fasciocutaneous flaps began gaining in popularity in the 1980s [35]. Fasciocutaneous flaps lack the muscular cushion of musculocutaneous flaps and depend on the deep fascia, subcutaneous tissue, and skin for its vascular supply. The theoretical advantage of fasciocutaneous flaps is the covering of bony pressure points only by fascia, subcutaneous fat, and skin directly, mirroring that of normal anatomy; in addition to the obvious advantage of muscle preservation. Studies of fasciocutaneous flaps have shown a reduction in donor site morbidity, minimal blood loss, decreased postoperative pain, shorter hospital stays, reduced costs, and preservation of muscle function [36,37]. When considering complications, Thiessen et al. reported no differences in infection, hematoma, seroma, dehiscence, and need for reoperation between fasciocutaneous and musculocutaneous flaps [38]. Similar findings by Sameem with $11.7 \%$ complication rate, $5.1 \%$ necrosis rate, $6.9 \%$ infection rate, and $11.2 \%$ recurrence rate [34] are supported by several other studies $[39,40]$.

Perforator based flaps have gained popularity since their use twenty years ago [41]. Perforator flaps contain vasculature that course from underlying vascular supply toward tissue surface. Advantages of the perforator flap include preservation of original vascular supply and longer pedicle lengths for flap advancement. However, perforator flaps are also more tedious to dissect $[41,42]$ and are more prone to venous congestion [43]. From a performance perspective, Sameem found perforator-based flaps to have worse complication rates but improved recurrence rate compared to both musculocutaneous and fasciocutaneous flaps [34]. Based on literature, musculocutaneous, fasciocutaneous, and perforator flaps could perhaps be more appropriately selected through advantages rather than possible complication or recurrence rates of the flap.

Although less commonly used, other flaps for pressure sores include free flaps. Free flaps can be taken from parascapular region, latissimusdorsi, or as fillet flaps from the leg and have been shown to produce good results [44]. Indications for free flap coverage include absence of local flap tissue especially in the multiply recurrent pressure sores. Biplanar flaps incorporate a transposed muscle flap with a rotated fasciocutaneous flap to cover the underlying muscle flap
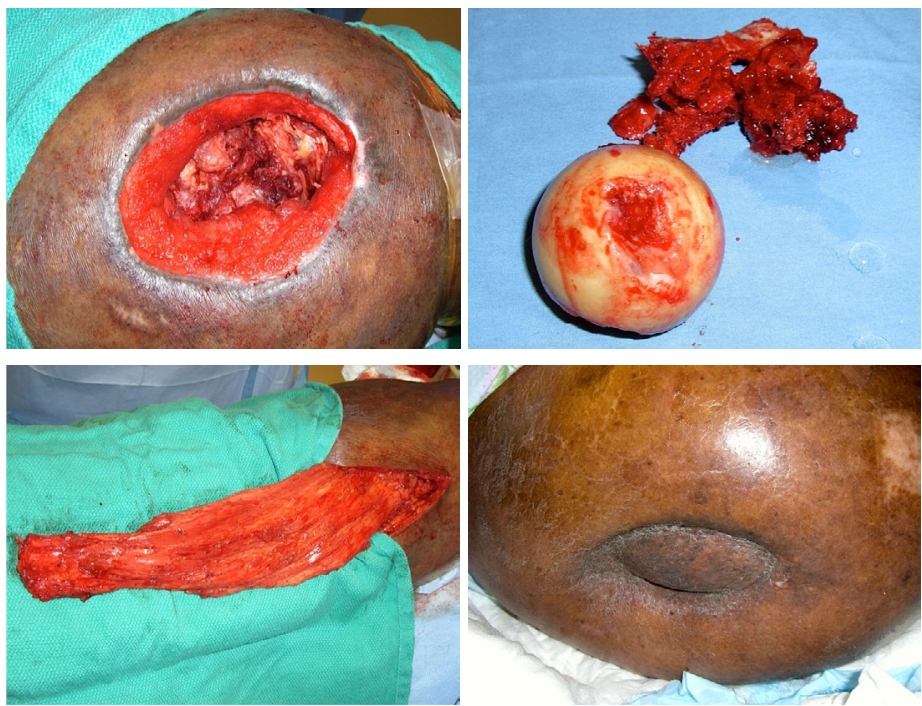

Figure 4: a) Right greater trochanter Stage IV ulcer in 60 year old patient who is non-ambulatory secondary to stroke. b) Girdlestone resection specimen. c) Vastuslateralis muscle flap at time of harvest. d) 5 months following vastuslateralis muscle flap and skin graft reconstruction.
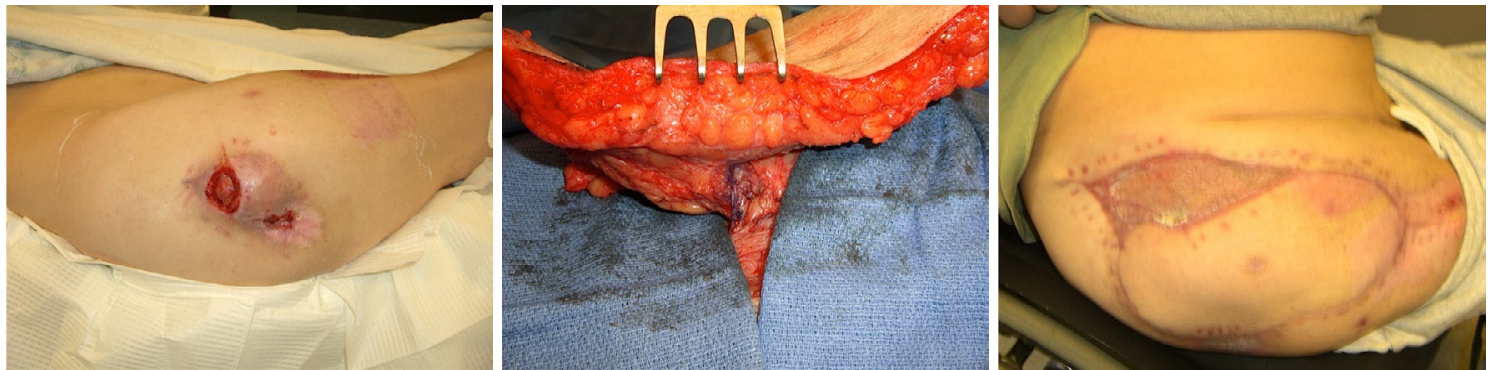

Figure 5: a) 37 year old male with history of right trochanteric decubitis ulcer occurring in previous flap reconstruction. b) Tensor fascia latae perforator flap at time of harvest. c) 4 months following reconstruction with skin graft reconstruction of donor site. 
Citation: Diaz S, Li X, Rodríguez L, Salgado CJ (2013) Update in the Surgical Management of Decubitus Ulcers. Anaplastology 2: 113. doi: 10.4172/2161-1173.1000113
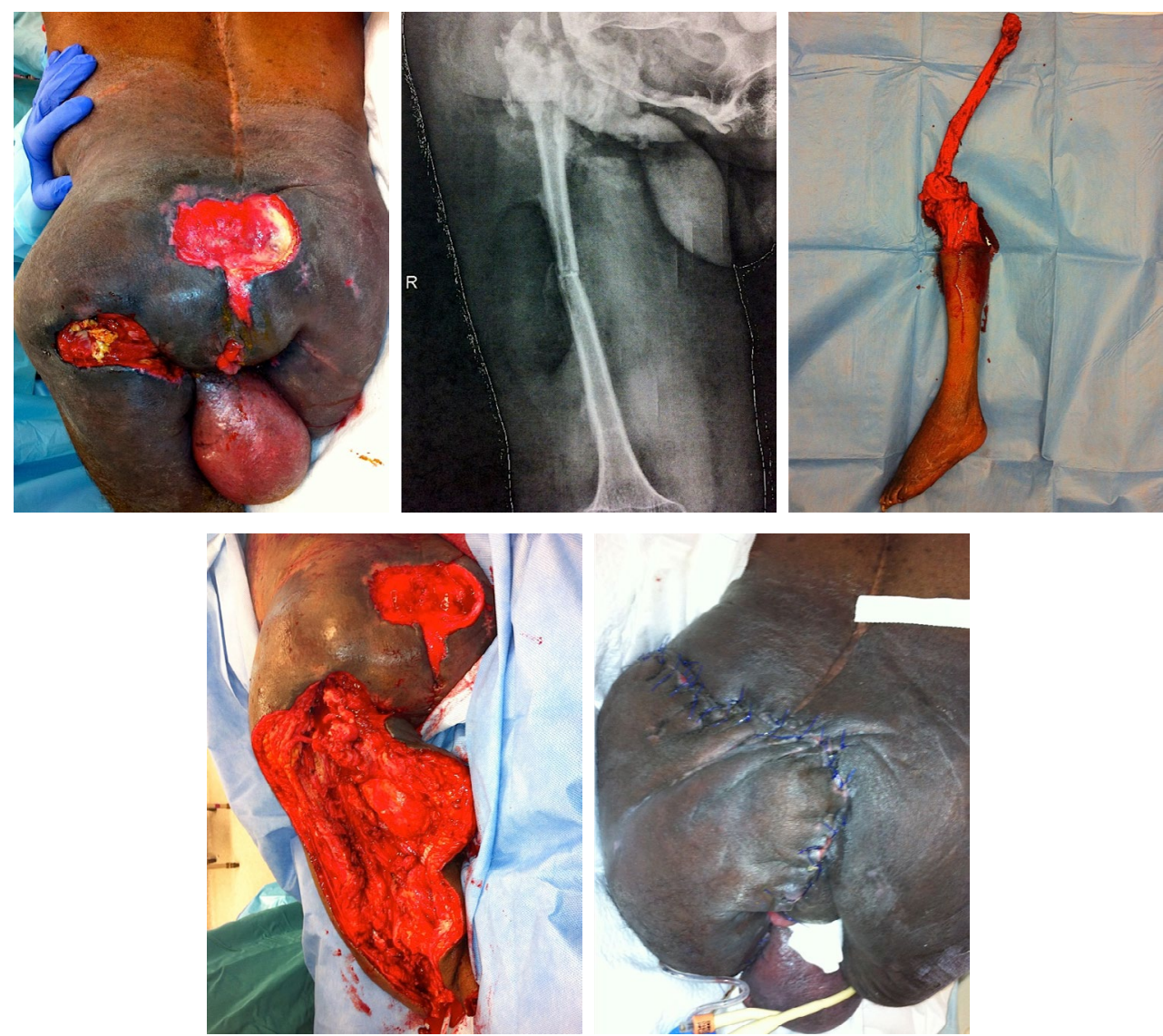

Figure 6: a) 39 year old with spinal cord lesion in past with long standing history of a sacral pressure sore and recent left femur fracture requiring Girdlestone resection. b) Xray of left femur fracture and diffuse osteomyelitis of the left hip with heterotopic ossification. c) Left lower extremity specimen. d) Anterior thigh flap used to reconstruct defect. e) 3 week postoperative view of above knee stump.

(Figure 3). Biplanar flaps have also been utilized with good results [45]. Amputations, hemicorpectomies, or salvage flaps should be reserved as a last resort for patients with recalcitrant ulcers or septic patients with uncontrollable infection. Surgery is not without risks since with any chronic wound, malignant degeneration into Marjolin's ulcer is a possibility. Biopsies are indicated in chronic wounds with changes in appearance especially when patients experience increased pain, foul discharge, or bleeding [46].

\section{Ischial Defects}

Ischial pressure sores occur in patients who remain in the sitting position for prolonged periods of time, being most of these patients paraplegic [8]. They usually have a minor skin defect accompanied by deep tissue loss and a large, penetrating ischial tuberosity [47], requiring adequate padding at the time of reconstruction. They are the most complicated pressure sore to treat and have the highest recurrence rate, between $20-75 \%[38,48-50]$, since patients almost always return to their chair-bound position [51]. If treated with non-surgical methods, the recurrence rate reaches $77 \%$ [9]. There have been various types of flaps suggested for the reconstruction of ischial defects, but among the most commonly used are the ones in the gluteal region and posterior thigh [48]. The latter present a disadvantage since their origin is in the leg, causing them to suffer shear forces with leg movement and closure of the flap under tension.

\section{Gluteus maximusmyocutaneous flap}

The gluteus maximusmyocutaneous flap, described by Minami et al. in 1977 [30], remains one of the first options in surgical management for ischial reconstruction [12,52]. It receives its vascular supply from the superior gluteal artery and can be designed as a rotational or an advancement flap. Among its advantages are that it can be revised and re-advanced if there is any recurrence, and its sutures do not lie on pressure zones [12]. It can also fill in undermined ulcers with skin removal, however if the defect is big, a combination of flaps may be needed $[22,53]$.

To harvest this flap the incision is made just lateral to the gluteal crease, extending it superior and laterally to the defect, but remaining medial to the greater trochanter. The muscle is then elevated from its inferior border by dissecting into the areolar plane, which is below the muscle and above the sciatic nerve. The dissection should be continued until an adequate size is acquired to fully fill the defect, and then the muscle is transected. Finally the flap is placed into position by suturing the excess muscle into the depth of the wound, and closure is performed by layers [30].

Although it is one of the first options among reconstruction, it compromises muscle function and should be avoided in patients that ambulate. It is also may be prone to post-operative skin breakdown because of tension [22], and has been shown to have a recurrence rate between $0-8.3 \%[34,54]$. 


\section{Inferior gluteus maximus island flap}

The gluteus muscle is divided in a superior and inferior half based on their blood supply, which in this case is the inferior gluteal artery. Then the flap is elevated, including only the inferior half of the muscle, and rotated into the defect. The donor site can be closed primarily [55]. A recurrence rate of $9.7 \%$ has been reported [34]

Variations that can be used in patients where ambulation should be conserved are:

- Split inferior gluteal muscle flap which is less debilitating [8], with an $8.3 \%$ recurrence rate [56].

- Inferior Gluteal Artery Perforator Flap, a fasciocutaneous flap, described for ischial pressure sores by Higgins et al. in 2002 [57], that takes its vascular supply form the inferior gluteal artery perforators, leaving the underlying gluteal muscle intact [58,59]. It is shaped elliptically, and then positioned parallel to the tension line [37]. It is versatile enough to allow various flap designs, allows closure without tension and preserves tissue for future flaps [58]. According to Kim et al., it has a recurrence rate of $21.7 \%$ [37].

\section{Posterior thigh flaps}

The posterior thigh flaps have been widely used in pressure sore reconstruction, mainly because they provide bulk and coverage, while maintaining tissue integrity for future flaps in case recurrence occurs [46]. Their main disadvantage is their origin in the thigh, which exposes them to friction against the ischial tuberosity when the patient extends or flexes extremities and to increased pressure when the patient remains seated [22].

\section{V-Y hamstring advancement flap}

As its name suggests, it is based on the Hamstring muscles (mainly the biceps femoris muscle, but can include the semitendinosus and semimembranosus muscles) and it receives its vascular supply from the biceps femoris perforators [22]. It is indicated in small to medium defects [8], whether primary or recurrent, and its versatility allows it to be used both in ambulatory patients and in those with spinal-cord lesions by just modifying its muscle content. It also has a bulky muscle component that protects the bony prominence and that could be used for large ischial defects [22]. It has a recurrence rate of $\sim 18 \%$ [34].

The flap landmarks are from the gluteal to the popliteal crease, and from the gracilis muscle to the fascia lata. The flap is elevated deep from the underlying fascia, with the sciatic nerve marking the deep landmarks. The biceps femoris long head is included in the flap, by separating it from the short head, as well as the semitendinosus and semimembranosus muscles, by transecting them at their origin and insertion tendon junction. If flexion of the knee must be preserved, these last two muscles are not included in the flap. Then the proximal part of the flap is advanced into the ischial defect and closed without tension, and the distal part is closed by V-Y technique $[53,60]$.

\section{Medial thigh advancement fasciocutaneous flap}

With its base on the posterior-medial thigh, this flap allows adequate coverage of the defect since it has a great degree of rotation [8]. As described by Homma et al., it receives its vascular supply mainly from the musculocutaneous perforators from either the adductor magnus muscle or the gracilis [61]. Its disadvantage is the amount of pressure and shear forces it endures since it is localized on the leg [58].
The flap is raised off the hamstring fascia, and then is rotated towards the ischial defect, and sutured with double layer closure. The distal part of the donor site should be skin grafted [53].

Ahluwalia et al. reported 7\% recurrence rate (when combined with the biceps femoris muscle), and Homma et al. a 27.3\% recurrence rate [62].

\section{Posterior thigh fasciocutaneous flap}

It is available if there is no deep scarring of the posterior thigh, and can be used with the gracilis flap to fill up the dead space [22]. Its recurrence rate has been reported to be 8 to $16 \%[34,63]$.

\section{Inferior gluteal posterior thigh flap}

This fasciocutaneous flap has been commonly used for ischial reconstruction, it is similar to the hamstring flap but does not include muscles. Its blood supply is from the descending branch of the inferior gluteal artery [53].

\section{Gracilismyocutaneous island}

The gracilis muscle flap is the most extensively used for free tissue transfer [58]. It is located in the medial thigh, and receives its vascular supply from a branch of the medial femoral circumflex artery. It is an excellent flap for small to medium defects, but should be used with caution in patients with atrophy since failure of the skin portion has been a problem. Other advantages are that transfer of the muscle leaves no functional deficit, and the donor site can be closed primarily [53]. Its recurrence rate has been reported to be between $8.3-14.3 \%$ [34].

The incision line must be planned with the patient in supine position with slight abduction, because the lax gracilis muscle might migrate when placing the patient in a lithotomy position. The skin paddle is designed posterior to this line. After the incision is made, the gracilis muscle is dissected distal to proximal, its tendon is divided and its proximal pedicle is preserved. Then a subcutaneous tunnel is created to pull the gracilis into the ischial cavity, and the donor site is closed primarily by layers $[47,53,58]$.

\section{Tensor fascia latae flap}

Although it is mostly used for trochanteric defects, this flap is indicated in patients with spinal cord injury below L3 because it brings sensitivity to the ischial area $[8,12]$. It is based on the ascending branch of the lateral circumflex femoral artery. It has a reliable pedicle, however, occasionally cannot quite reach the zone of the defect, causing its distal part to undergo necrosis rather easily [63]. 21.1\% recurrence rate has been reported [34].

Other flaps have been mentioned in the literature like the Adipofascial turnover fasciocutaneous flap (recurrence rate between 6.7-9.1\%) [34,63], the "three muscle flap" which is for big, deep pressure sores and depends on the descending branch of the lateral femoral circumflex artery for its vascular supply [64], lateral and anterior thigh fasciocutaneous flap, rectus abdominismyocutaneous flap, adductor muscle perforator flap, and sclerotherapy, among others [8,58].

\section{Sacral Defects}

Sacral pressure sores are commonly seen in patients that remain in the supine position. They can be managed with skin grafting if the defect is small and/or secondary to acute/short-term disability. However, their recurrence rate has been as high as $70 \%$ with this method [8], demonstrating that more bulk is necessary to achieve healing. For this 
reason flaps have been used. Amongst the most common flaps for this area are the ones based on the Gluteus Maximus [22], because of its proximity to the lesion. Yamamoto et al. reported a total recurrence rate of $21 \%$, with fasciocutaneous flaps recurring $17 \%$ of the time [50]. Additionally to flaps, Wong and Ip recommend the release of flexion contractures since it facilitates passive movement and nursing care [65]. This is commonly done with botulinum toxin injections.

\section{Gluteus maximus musculocutaneous flap}

Just as in the ischial defect, the gluteus maximus musculocutaneous flap remains the first choice for sacral pressure sore reconstruction [12]. In this case it is based inferior and medially, and its vascular supply is the superior gluteal artery. When elevating this flap, the key point is the pirifomis muscle since it is through there where the vascular supply emerges [30]. For more details refer to the ischial defects section. According to the review done by Sameem et al., the recurrence rate reaches $7.7 \%$ [34].

\section{V-Y gluteus maximus flap}

Since Parry and Mathes introduced the bilateral gluteal advancement flap, it has remained a popular option for sacral pressure sore management. It can be used as a musculocutaneous or fasciocutaneous flap, receives its vasculature form the gluteal artery and its innervation from the inferior gluteal nerve. Its recurrence rate approximates $6.3 \%$ [34].

When harvesting this flap, you elevate both superior and inferior arms, advance them and close in layers in a straight fashion or in "zigzag"; the later diminishes tension and allows more healthy tissue to cover the defect [66].

\section{Superior gluteal artery island flap}

A musculucotaneous flap similar to the inferior gluteal island flap for ischial defects is the superior gluteal island flap and is a good option for sacral defects that provides adequate tissue coverage and protection, and preserves muscle function by leaving the inferior gluteal nerve intact, so it can be used in ambulant patients [55]. Korambayil et al. reported no recurrence [67].

\section{Superior gluteal artery perforator flap}

This fasciocutaneous flap is commonly used in breast reconstruction, but is also used in sacral ulcer repair, especially for small defects. Its pedicle can be rotated to fit the defect, but it is not a flap that can easily be revised [22]. According to the review published by Sameem et al., there were no reported recurrence rates with this flap [34].

\section{Gluteal rotation flap}

A fasciocutaneous flap, with an inferior base, and vascular supply from the superficial branch of the superior gluteal artery and from the inferior gluteal artery [53]. Despite this excellent blood supply, Wong et al. found a recurrence rate of $24 \%$ compared to cero percent when they used musculocutaneous flaps. The surgical technique is similar to the musculocutaneous flap, except for the fact that the muscle is spared. It also has the advantage that it can be re-advanced / rotated [65]

When there is no more available tissue, other flaps should be considered, among the most common secondary treatment flaps are the transverse back flap [9], filet leg flap, and latissimusdorsi flap [34,44].

\section{Trochanteric Defects}

Trochanteric ulcers arise secondary to direct pressure from the greater trochanter, and are typically found in patients lying in prolonged lateral decubitus position. They are less common than ischial and sacral ulcers, but still represent $12-19 \%$ of all pressure sores $[68,69]$. Nonsurgical therapy is estimated to work in $41 \%$ of patients according to one study [70], while surgery is typically reserved for Stage III and IV ulcers. Because of the tension on the lateral hip tissue, direct wound closure is usually not possible. Ulcer recurrence is mainly secondary to the insensate wound site with rates as high as $80 \%$ [71]. The ulcer could extend into the trochanteric bursa causing septic destruction of the hip joint. In these situations a Girdlestone resection may be required.

Tensor Fascia Lata (TFL) musculocutaneous flap and its modifications are the most commonly used flaps in trochanteric ulcer closure [72-74]. The TFL is supplied by the ascending branch of the lateral femoral circumflex artery. Sensory innervation is by the cutaneous sensory nerve of the thigh and lateral femoral cutaneous nerve distally. Motor innervation is through branches of the superior gluteal nerve. Anteriorly, the flap is located within the boundaries of the anterior superior iliac spine axis to the lateral patella and posteriorly, the axis of the femur. The flap is lifted distal to proximal with proper identification of descending and ascending branches of the lateral circumflex femoral artery, respectively. The vascular pedicle of the lateral circumflex femoral artery is typically $10 \mathrm{~cm}$ below the anterior superior iliac spine. The length of the flap is determined by the distance between the pivot point of the flap and the posterior border of the ulcer.

The TFL is an ideal muscle for this flap because of its lack of use as a functional muscle and its $10 \mathrm{~cm}$ pedicle length. In addition, its lumbar innervation helps provide sensation for patients with spinal injuries. Good results have typically been reported with this flap and its modifications $[75,76]$. TFL flaps as a VY advancement flap is typically used for ulcers that are small to medium sized [74]. For larger ulcers, the TFL can be used as a rotation flap. Disadvantages of the TFL flap include necrosis of distal flap secondary to poor blood supply especially when extended to $8-10 \mathrm{~cm}$ proximal to knee [77-79]. In addition, excessive tension resulting in suture separation has also been reported at the donor site $[80,81]$. Donor defects can be closed with a splitthickness skin graft. Aesthetically, the TFL also has the disadvantage of dog-ear deformity. Attempts to alleviate these issues have led modifications to bilobed and duck flaps with good results $[76,80,81]$.

Second line treatments for trochanteric ulcers include anterolateral thigh flap, vastus lateralis flap, rectus femoris muscle flap, and gluteus maximus flap $[53,82,83]$. These flaps can also be combined to form chimeric flaps [84]. The Anterolateral Thigh Flap (ALT) was first developed by Kimata et al. for perineal reconstruction with subsequent application to trochanteric defects with success [85-88]. Advantages of the ALT include a long vascular pedicle and a relatively unrestricted arc of rotation. Disadvantages include tedious and time consuming dissection. Attempts to simply for the ALT through myocutaneous instead of pedicled flaps have been reported by Wang et al. with good results [89]. Other reported flaps include gluteus medius flap, random thigh flap, and random bipedicled flap (Figure 5).

The major complication of trochanteric ulcers is septic arthritis with joint destruction. Joint and bone debridement followed by the Girdlestone procedure and muscle flap closure is the treatment of choice [90-92]. Rectus femoris flaps can be used for small defects while a vastus lateralis muscle flap or a combined vastus TFL flap can be used for larger defects (Figure 4). 
Citation: Diaz S, Li X, Rodríguez L, Salgado CJ (2013) Update in the Surgical Management of Decubitus Ulcers. Anaplastology 2: 113. doi: 10.4172/2161-1173.1000113

Page 8 of 10

\section{Post-Operative Care}

Post-operative management for pressures sores include appropriate wound care as to reduce infection, tension, and dehiscence. Nonsurgical preventive measures should still be applied to post-operative patients. Traditionally 6 weeks of immobilization is practiced, while Kierney et al. recommended 3 weeks of immobilization with air-fluid Clinitron or KinAire beds [39]. In addition, physical therapy is also important to prevent contractions, decrease DVT, and other typical post-operative complications. Progressive sitting should begin with gradual increase to pressure release maneuvers. However, special care must be taken in spinal cord patients as denervated tissue heals less efficiently [93]. Ulcer recurrence rates following flap intervention typically range between $13 \%$ to $31 \%[39,94]$ and the most vulnerable time for flap failure range from 15-22 months post operatively [71,95]. Recurrences and flap failures are due to a multitude of factors. Age $<45$ years at surgery time, history of same-site failure, poor diabetes control, prealbumin less than $20 \mathrm{mg} / \mathrm{dL}$ and ischial wound location are found to be significant predictors of dehiscence and recurrence [49]. The recurrence in younger population is hypothesized to be secondary to poor compliance with long bed rests and higher incidence of traumatic denervating injuries. Interestingly, while one study suggested that poor hygiene, malnutrition, and anemia are associated with recurrences [96], Larson, however, found that preoperative albumin and prealbumin levels are not associated [29].

\section{References}

1. Aggarwal A, Sangwan SS, Siwach RC, Batra KM (1996) Gluteus maximus island flap for the repair of sacral pressure sores. Spinal Cord 34: 346-350.

2. Moore ZEH, Cowman S (2012) Repositioning for treating pressure ulcers. Cochrane Database Syst Rev 9: CD006898.

3. Vandenkerkhof EG, Friedberg E, Harrison MB (2011) Prevalence and Risk of Pressure Ulcers in Acute Care Following Implementation of Practice Guidelines: Annual Pressure Ulcer Prevalence Census 1994-2008. J Health Qual.

4. Levine SM, Sinno S, Levine JP, Saadeh PB (2012) An evidence-based approach to the surgical management of pressure ulcers. Ann Plast Surg 69: 482-484

5. Park-Lee E, Caffrey C (2009) Pressure ulcers among nursing home residents: United States, 2004. NCHS Data Brief 1-8.

6. Giuglea C, Marinescu S, Florescu IP, Jecan C (2010) Pressure sores--a constant problem for plegic patients and a permanent challenge for plastic surgery. J Med Life 3: 149-153.

7. Brem H, Lyder C (2004) Protocol for the successful treatment of pressure ulcers. Am J Surg 188: 9-17.

8. Bauer J, Phillips LG (2008) MOC-PSSM CME article: Pressure sores. Plast Reconstr Surg 121: 1-10.

9. Bass MJ, Phillips LG (2007) Pressure sores. Curr Probl Surg 44: 101-143.

10. Cakmak SK, Gui U, Ozer S, Yigit Z, Gonu M (2009) Risk factors for pressure ulcers. Adv Skin Wound Care 22: 412-415.

11. Thoroddsen A (1999) Pressure sore prevalence: a national survey. J Clin Nurs 8: $170-179$.

12. Sørensen JL, Jørgensen B, Gottrup F (2004) Surgical treatment of pressure ulcers. Am J Surg 188: 42-51.

13. Reddy M, Gill SS, Kalkar SR, Wu W, Anderson PJ, et al. (2008) Treatment of pressure ulcers: a systematic review. JAMA 300: 2647-2662.

14. Krapfl LA, Gray M (2008) Does regular repositioning prevent pressure ulcers? J Wound Ostomy Continence Nurs 35: 571-577.

15. McInnes E, Dumville JC, Jammali-Blasi A, Bell-Syer SE (2011) Support surfaces for treating pressure ulcers. Cochrane Database Syst Rev : CD009490.

16. Regan MA, Teasell RW, Wolfe DL, Keast D, Mortenson WB, et al. (2009) A systematic review of therapeutic interventions for pressure ulcers after spinal cord injury. Arch Phys Med Rehabil 90: 213-231.

17. Revis DR. E-Medicine article on "Decubitus Ulcers"

18. Ubbink D, Westerbos S, Evans D, Land L, Vermeulen H (2011) Topical negative pressure for treating chronic wounds. Cochrane Database Syst Rev 3:CD001898.

19. Gregor S, Maegele M, Sauerland S, Krahn JF, Peinemann F, et al. (2008) Negative pressure wound therapy: a vacuum of evidence? Arch Surg 143: 189196

20. Roeckl-Wiedmann I, Bennett M, Kranke $P$ (2005) Systematic review of hyperbaric oxygen in the management of chronic wounds. Br J Surg 92: 24-32.

21. Singh R, Singh R, Rohilla RK, Siwach R, Verma V, et al. (2010) Surgery for pressure ulcers improves general health and quality of life in patients with spinal cord injury. J Spinal Cord Med 33: 396-400.

22. Rubayi S, Chandrasekhar BS (2011) Trunk, abdomen, and pressure sore reconstruction. Plast Reconstr Surg 128: 201e-215e.

23. Smith F, Dryburgh N, Donaldson J, Mitchell M (2011) Debridement for surgical wounds. Cochrane Database Syst Rev 3: CD006214.

24. Rodeheaver GT (1999) Pressure ulcer debridement and cleansing: a review of current literature. Ostomy Wound Manage 45: 80S-85S.

25. Salgado CJ, Colen LB (2009) Osteomyelitis. Semin Plast Surg 23: 57-58.

26. Gusenoff JA, Redett RJ, Nahabedian MY (2002) Outcomes for surgical coverage of pressure sores in nonambulatory, nonparaplegic, elderly patients. Ann Plast Surg 48: 633-640.

27. Giebel GD, Jaeger K (1987) Variants in the management of decubitus ulcers Hand chir Mikrochir Plast Chir 19: 109-112.

28. Dardour JC, Vilain R, Castro D (1984) Evaluation of 10 years of surgical treatment for decubitus ulcer. Sem Hop 60: 1051-1056.

29. Larson DL, Hudak KA, Waring WP, Orr MR, Simonelic K (2012) Protocol management of late-stage pressure ulcers: a 5-year retrospective study of 101 consecutive patients with 179 ulcers. Plast Reconstr Surg 129: 897-904

30. Minami RT, Mills R, Pardoe R (1977) Gluteus maximusmyocutaneous flaps for repair of pressure sores. Plast Reconstr Surg 60: 242-249.

31. Gosain A, Chang N, Mathes S, Hunt TK, Vasconez L (1990) A study of the relationship between blood flow and bacterial inoculation in musculocutaneous and fasciocutaneous flaps. Plast Reconstr Surg 86: 1152-1162.

32. Daniel RK, Faibisoff B (1982) Muscle coverage of pressure points--the role of myocutaneous flaps. Ann Plast Surg 8: 446-452.

33. Gray BC, Salzberg CA, Petro JA, Salisbury RE (1990) The expanded myocutaneous flap for reconstruction of the difficult pressure sore. Decubitus 3: 17-20.

34. Sameem M, Au M, Wood T, Farrokhyar F, Mahoney J (2012) A systematic review of complication and recurrence rates of musculocutaneous fasciocutaneous, and perforator-based flaps for treatment of pressure sores. Plast Reconstr Surg 130: 67e-77e.

35. Yamamoto Y, Ohura T, Shintomi Y, Sugihara T, Nohira K, et al. (1993) Superiority of the fasciocutaneous flap in reconstruction of sacral pressure sores. Ann Plast Surg 30: 116-121.

36. Seyhan T, Ertas NM, Bahar T, Borman H (2008) Simplified and versatile use of gluteal perforator flaps for pressure sores. Ann Plast Surg 60: 673-678.

37. Kim YS, Lew DH, Roh TS, Yoo WM, Lee WJ, et al. (2009) Inferior gluteal artery perforator flap: a viable alternative for ischial pressure sores. J Plast Reconstr Aesthet Surg 62: 1347-1354.

38. Thiessen FE, Andrades P, Blondeel PN, Hamdi M, Roche N, et al. (2011) Flap surgery for pressure sores: should the underlying muscle be transferred or not? J Plast Reconstr Aesthet Surg 64: 84-90.

39. Kierney PC, Engrav LH, Isik FF, Esselman PC, Cardenas DD, et al. (1998) Results of 268 pressure sores in 158 patients managed jointly by plastic surgery and rehabilitation medicine. Plast Reconstr Surg 102: 765-772.

40. Goodman CM, Cohen V, Armenta A, Thornby J, Netscher DT (1999) Evaluation of results and treatment variables for pressure ulcers in 48 veteran spinal cordinjured patients. Ann Plast Surg 42: 665-672. 
Citation: Diaz S, Li X, Rodríguez L, Salgado CJ (2013) Update in the Surgical Management of Decubitus Ulcers. Anaplastology 2: 113. doi: 10.4172/2161-1173.1000113

Page 9 of 10

41. Koshima I, Moriguchi T, Soeda S, Kawata S, Ohta S, et al. (1993) The gluteal perforator-based flap for repair of sacral pressure sores. Plast Reconstr Surg 91: 678-683

42. Nojima K, Brown SA, Acikel C, Arbique G, Ozturk S, et al. (2005) Defining vascular supply and territory of thinned perforator flaps: part I. Anterolateral thigh perforator flap. Plast Reconstr Surg 116: 182-193.

43. Lee BT, Lin SJ, Bar-Meir ED, Borud LJ, Upton J (2010) Pedicled perforator flaps: a new principle in reconstructive surgery. Plast Reconstr Surg 125: 201 208

44. Lemaire V, Boulanger K, Heymans $\mathrm{O}$ (2008) Free flaps for pressure sore coverage. Ann Plast Surg 60: 631-634.

45. Mehta A, Baker TA, Shoup M, Brownson K, Amde S, et al. (2012) Biplanar flap reconstruction for pressure ulcers: experience in patients with immobility from chronic spinal cord injuries. Am J Surg 203: 303-306.

46. Tchanque-Fossuo CN, Kuzon WM Jr (2011) An evidence-based approach to pressure sores. Plast Reconstr Surg 127: 932-939.

47. El-Sabbagh AH (2011) The accordion gracilis muscle flap: a new design for coverage of recurrent and complicated ischeal pressure sores. Int Wound $J$ 8: 447-453.

48. Unal C, Ozdemir J, Yirmibesoglu O, Yucel E, Agir H (2012) Use of inferior gluteal artery and posterior thigh perforators in management of ischial pressure sores with limited donor sites for flap coverage. Ann Plast Surg 69: 67-72.

49. Keys KA, Daniali LN, Warner KJ, Mathes DW (2010) Multivariate predictors of failure after flap coverage of pressure ulcers. Plast Reconstr Surg 125: 17251734.

50. Yamamoto Y, Tsutsumida A, Murazumi M, Sugihara T (1997) Long-term outcome of pressure sores treated with flap coverage. Plast Reconstr Surg 100: 1212-1217.

51. Bauer JD, Mancoll JS, Phillips LG (2007) In Grabb and Smith's Plastic Surgery. (6th edn). Philadelphia, PA: Lippincott Williams \& Wilkins.

52. Foster RD, Anthony JP, Mathes SJ, Hoffman WY (1997) Ischial pressure sore coverage: a rationale for flap selection. Br J Plast Surg 50: 374-379.

53. Strauch B, Vasconez LO, Hall-Findlay EJ, Lee BT. InGrabb's Encyclopedia of Flaps (3rdedn). PA: Lippincott Williams \& Wilkins, Philadelphia, USA.

54. Jósvay J, Sashegyi M, Kelemen P, Donáth A (2005) Clinical experience with the hatchet-shaped gluteus maximusmusculocutaneous flap. Ann Plast Surg 55: 179-182.

55. Sharma RK (2001) Split gluteus maximus island flaps for concomitant closure of ischial and sacral pressure sores. Ann Plast Surg 46: 52-54.

56. Borgognone A, Anniboletti T, De Vita F, Schirosi M, Palombo P (2010) Ischiatic pressure sores: our experience in coupling a split-muscle flap and a fasciocutaneous flap in a 'criss-cross' way. Spinal Cord 48: 770-773.

57. Higgins JP, Orlando GS, Blondeel PN (2002) Ischial pressure sore reconstruction using an inferior gluteal artery perforator (IGAP) flap. Br J Plast Surg 55: 83-85.

58. Lee SS, Huang SH, Chen MC, Chang KP, Lai CS, et al. (2009) Management of recurrent ischial pressure sore with gracilis muscle flap and $\mathrm{V}-\mathrm{Y}$ profundafemoris artery perforator-based flap. J Plast Reconstr Aesthet Surg 62: 1339-1346.

59. WindhoferCh, Michlits W, Gruber S, Papp Ch (2010) Reconstruction in the buttock region using the local fasciocutaneousinfragluteal $(\mathrm{FCl})$ flap. J Plast Reconstr Aesthet Surg 63: 126-132.

60. Kroll SS, Hamilton S (1989) Multiple and repetitive uses of the extended hamstring V-Y myocutaneous flap. Plast Reconstr Surg 84: 296-302.

61. Homma K, Murakami G, Fujioka H, Fujita T, Imai A, et al. (2001) Treatment of ischial pressure ulcers with a posteromedial thigh fasciocutaneous flap. Plast Reconstr Surg 108: 1990-1996.

62. Ahluwalia R, Martin D, Mahoney JL (2010) The operative treatment of pressure wounds: a 10-year experience in flap selection. Int Wound J 7: 103-106.

63. Lin MT, Chang KP, Lin SD, Lai CS, Yang YL (2004) Tensor fasciae latae combined with tangentially split vastuslateralismusculocutaneous flap for the reconstruction of pressure sores. Ann Plast Surg 53: 343-347.

64. Acartürk TO (2009) Treatment of large ischial ulcers communicating with the hip joint with proximal femoral resection and reconstruction with a combined vastuslateralis, vastusintermedius and rectus femorismusculocutaneous flap. $\mathrm{J}$ Plast Reconstr Aesthet Surg 62: 1497-1502.

65. Wong TC, Ip FK (2006) Comparison of gluteal fasciocutaneous rotational flaps and myocutaneous flaps for the treatment of sacral sores. IntOrthop 30: 64-67.

66. Ay A, Aytekin O, Aytekin A (2003) Interdigitatingfasciocutaneous gluteal V-Y advancement flaps for reconstruction of sacral defects. Ann Plast Surg 50: 636-638.

67. Korambayil PM, Allalasundaram K, Balakrishnan T (2010) Perforator propeller flaps for sacral and ischial soft tissue reconstruction. Indian J Plast Surg 43 : 151-157.

68. YEOMAN MP, HARDY AG (1954) The pathology and treatment of pressure sores in paraplegics. Br J Plast Surg 7: 179-192.

69. DANSEREAU JG, CONWAY H (1964) CLOSURE OF DECUBITI IN PARAPLEGICS. REPORT OF 2000 CASES. Plast Reconstr Surg 33: 474-480.

70. CONWAY H, GRIFFITH BH (1956) Plastic surgery for closure of decubitus ulcers in patients with paraplegia; based on experience with 1,000 cases. Am J Surg 91: 946-975.

71. Evans GR, Dufresne CR, Manson PN (1994) Surgical correction of pressure ulcers in an urban center: is it efficacious? Adv Wound Care 7: 40-46.

72. Bergstrom N (1994) Treatment of Pressure ulcers. Rockville, MD: US Dept of Health and Human Services, Public Health Service, Agency for Health Care Policy and Research. Clinical practice guideline, technical report no. 15 AHCPR Publication 96-N014-96-N015

73. Nahai F, Silverton JS, Hill HL, Vasconez LO (1978) The tensor fascia latamusculocutaneous flap. Ann Plast Surg 1: 372-379.

74. Siddiqui A, Wiedrich T, Lewis VL Jr (1993) Tensor fascia lata V-Y retropositionmyocutaneous flap: clinical experience. Ann Plast Surg 31: 313-317.

75. Jósvay J, Sashegyi M, Kelemen P, Donáth A (2006) Modified tensor fascia latamusculofasciocutaneous flap for the coverage of trochanteric pressure sores. J Plast Reconstr Aesthet Surg 59: 137-141.

76. Burm JS, Yang WY (2011) Distally extended tensor fascia lata flap including the wide iliotibial tract for reconstruction of trochanteric pressure sores. J Plast Reconstr Aesthet Surg 64: 1197-1201.

77. Nahai F, Hill L, Hester TR (1979) Experiences with the tensor fascia lata flap. Plast Reconstr Surg 63: 788-799.

78. Gosain AK, Yan JG, Aydin MA, Das DK, Sanger JR (2002) The vascular supply of the extended tensor fasciae latae flap: how far can the skin paddle extend? Plast Reconstr Surg 110: 1655-1661.

79. Safak T, Klebuc MJ, Keçik A, Shenaq SM (1996) The subcutaneous pedicle tensor fascia lata flap. Plast Reconstr Surg 97: 765-774.

80. Lynch SM (1981) Thebilobed tensor fascia latamyocutaneous flap. Plast Reconstr Surg 67: 796-798.

81. Aslan G, Tuncali D, Bingul F, Ates L, Yavuz N (2005) The "duck" modification of the tensor fascia lata flap. Ann Plast Surg 54: 637-639.

82. Drimmer MA, Krasna MJ (1987) Thevastuslateralismyocutaneous flap. Plast Reconstr Surg79: 560-566

83. Linder RM, Morris D (1990) The surgical management of pressure ulcers: a systematic approach based on staging. Decubitus 3: 32-38.

84. Wei FC, Jain V, Celik N, Chen HC, Chuang DC, et al. (2002) Have we found an ideal soft-tissue flap? An experience with 672 anterolateral thigh flaps. Plast Reconstr Surg 109: 2219-2226.

85. Kimata Y, Uchiyama K, Ebihara S, Nakatsuka T, Harii K (1998) Anatomic variations and technical problems of the anterolateral thigh flap: a report of 74 cases. Plast Reconstr Surg 102: 1517-1523.

86. Tzeng YS, Yu CC, Chou TD, Chen TM, Chen SG (2008) Proximalpedicled anterolateral thigh flap for reconstruction of trochanteric defect. Ann Plast Surg 61: 79-82.

87. Gravvanis Al, Tsoutsos DA, Karakitsos D, Panayotou P, Iconomou T, et al. (2006) Application of the pedicled anterolateral thigh flap to defects from the pelvis to the knee. Microsurgery 26: 432-438.

88. Hallock GG (2005) The proximal pedicled anterolateral thigh flap for lower limb coverage. Ann Plast Surg 55: 466-469. 
Citation: Diaz S, Li X, Rodríguez L, Salgado CJ (2013) Update in the Surgical Management of Decubitus Ulcers. Anaplastology 2: 113. doi: 10.4172/2161-1173.1000113

Page 10 of 10

89. Wang CH, Chen SY, Fu JP, Dai NT, Chen SL, et al. (2011) Reconstruction of trochanteric pressure sores with pedicled anterolateral thigh myocutaneous flaps. J Plast Reconstr Aesthet Surg 64: 671-676.

90. Girdlestone GR (1982) Acute pyogenic arthritis of the hip: An operation giving free access and effective drainage. Clin Orthop Relat Rees 170: 3-7.

91. Arnold PG, Witzke DJ (1983) Management of failed total hip arthroplasty with muscle flaps. Ann Plast Surg 11: 474-478.

92. Rubayi S, Pompan D, Garland D (1991) Proximal femoral resection and myocutaneous flap for treatment of pressure ulcers in spinal injury patients. Ann Plast Surg 27: 132-138.
93. Barker AR, Rosson GD, Dellon AL (2006) Wound healing in denervated tissue. Ann Plast Surg 57: 339-342.

94. Schryvers OI, Stranc MF, Nance PW (2000) Surgical treatment of pressure ulcers: 20-year experience. Arch Phys Med Rehabil 81: 1556-1562.

95. Tavakoli K, Rutkowski S, Cope C, Hassall M, Barnett R, et al. (1999) Recurrence rates of ischial sores in para- and tetraplegics treated with hamstring flaps: an 8-year study. Br J Plast Surg 52: 476-479.

96. GRIFFITH BH, SCHULTZ RC (1961) The prevention and surgical treatment of recurrent decubitus ulcers in patients with paraplegia. Plast Reconstr Surg Transplant Bull 27: 248-260. 